\section{Comparison of Supplemental Lighting from High-pressure Sodium Lamps and Light-emitting Diodes during Bedding Plant Seedling Production}

\author{
Wesley C. Randall and Roberto G. Lopez ${ }^{1,2}$ \\ Department of Horticulture and Landscape Architecture, Purdue University, \\ West Lafayette, IN 47907
}

Additional index words. daily light integral, HPS, LEDs, light quality, plugs

\begin{abstract}
Annual bedding plant seedlings or plugs are considered high quality when they are compact, fully rooted transplants with a large stem caliper and high root dry mass. Greenhouses in northern latitudes rely on supplemental lighting (SL) from high-pressure sodium lamps (HPS) during winter months to achieve high-quality, finished plugs. Lightemitting diodes (LEDs) offer higher energy efficiencies, a long operating life, and precise waveband specificity that can eliminate wavebands not considered useful. Seedlings of Antirrhinum, Catharanthus, Celosia, Impatiens, Pelargonium, Petunia, Tagetes, Salvia, and Viola were grown at $21^{\circ} \mathrm{C}$ under a 16-hour photoperiod of ambient solar light and SL of $100 \mu \mathrm{mol} \cdot \mathrm{m}^{-2} \cdot \mathrm{s}^{-1}$ from either HPS lamps or LED arrays with varying proportions (\%) of red:blue light (100:0, 85:15, or 70:30). Height of Catharanthus, Celosia, Impatiens, Petunia, Tagetes, Salvia, and Viola was $31 \%, 29 \%, 31 \%, 55 \%, 20 \%, 9 \%$, and $35 \%$ shorter, respectively, for seedlings grown under the 85:15 red:blue LEDs compared with those grown under HPS lamps. Additionally, stem caliper of Antirrhinum, Pelargonium, and Tagetes was $16 \%, 8 \%$, and $13 \%$ larger, respectively, for seedlings grown under the 85:15 red:blue LEDs compared with seedlings grown under HPS lamps. The quality index (QI), a quantitative measurement of quality, was similar for Antirrhinum, Catharanthus, Impatiens, Pelargonium, and Tagetes grown under LEDs and HPS lamps. However, it was significantly higher for Petunia, Salvia, and Viola under 85:15, 70:30, and 100:0 red:blue LEDs than under HPS lamps, respectively. These results indicate that seedling quality for the majority of the species tested under SL from LEDs providing both red and blue light was similar or higher than those grown under HPS lamps.
\end{abstract}

Annual bedding plant sales for the 15 topproducing states were over $\$ 1.4$ billion in 2012, the highest of any sector of the U.S. commercial floriculture industry (U.S. Dept. of Agriculture, 2013). Advancements in production of bedding plant seedlings, also known as young plants or plugs, have led to a large increase in finish plant quality and profitability (Armitage and Kaczperski, 1994; Kuehny et al., 2001). Young plant production occurs in late winter and early spring when

Received for publication 27 Jan. 2014. Accepted for publication 6 Mar. 2014.

We gratefully acknowledge Rob Eddy, Michael Ortiz, Christopher Currey, Joshua Gerovac, Camille Mahan, Jenna Buschkoetter, Alyssa Hilligoss, and Bryce Patz for greenhouse and laboratory assistance; Judy Santini for experimental design and statistical consultation; funding from the USDA-NIFA SCRI grant No. 2010-51181-21369; and funding and LED lighting from Philips Lighting and Hort Americas. We also thank Ball Horticultural Co. for seed and Heartland Growers for sowing seed.

The use of trade names in this publication does not imply endorsement by Purdue University of products named nor criticism of similar ones not mentioned.

${ }^{1}$ Associate Professor and Extension Specialist.

${ }^{2}$ To whom reprint requests should be addressed; e-mail rglopez@purdue.edu the integrated photosynthetic photon flux $(P P F)$, or daily light integral (DLI), can be 1 to $5 \mathrm{~mol} \cdot \mathrm{m}^{-2} \cdot \mathrm{d}^{-1}$ or lower during cloudy weather in northern latitudes (Lopez and Runkle, 2008). Previous studies indicate that young and finished plant growth and quality are diminished by low DLI (Currey et al., 2012; Faust et al., 2005; Hutchinson et al., 2012; Lopez and Runkle, 2008; Oh et al., 2010). A DLI of 10 to $12 \mathrm{~mol} \cdot \mathrm{m}^{-2} \cdot \mathrm{d}^{-1}$ has been shown to be a desirable minimum recommendation for growing high-quality young plants (Currey et al., 2012; Lopez and Runkle, 2008; Oh et al., 2010).

Previously, the only way for young-plant producers to appreciably increase ambient greenhouse DLI was to provide supplemental lighting (SL) from high-intensity discharge (HID) lights. High-pressure sodium (HPS) lamps are the most commonly used HID light sources, and several characteristics contribute to their use. However, HPS lamps primarily emit light in the spectral range of 565 to $700 \mathrm{~nm}$, which is primarily yellow (565 to $590 \mathrm{~nm}$ ), orange (590 to $625 \mathrm{~nm})$, and red (625 to $700 \mathrm{~nm}$ ), and have a peak at $589 \mathrm{~nm}$. HPS lamps are $\approx 25 \%$ to $30 \%$ efficient with a lifespan of 10,000 luminous hours or more. Up to $75 \%$ of the energy not converted to light is emitted as radiant heat energy causing the surface of HPS lamps to reach temperatures as high as $450{ }^{\circ} \mathrm{C}$ and requires separation of lamps from plants to prevent leaf scorch (Fisher and Both, 2004; Nelson, 2012; Sherrard, 2003; Spaargaren, 2001).

LEDs are solid-state, semiconducting diodes that can emit narrow spectra of light from $\approx 250 \mathrm{~nm}$ to $1000 \mathrm{~nm}$ or greater and have been considered for use as sole source and SL (Barta et al., 1992; Bourget, 2008; Bula et al., 1991; Massa et al., 2008). The peak wavelengths of greatest interest for studies of plant growth and development include blue $(450 \mathrm{~nm})$, red $(660 \mathrm{~nm})$, and far-red $(730 \mathrm{~nm})$. Recently, LEDs have achieved an efficiency of $38 \%$ (red) to $50 \%$ (blue) converting electrical energy to photons (Philips Lumileds, 2011) and have an estimated lifespan of 50,000 h or greater (Bourget, 2008). Light-emitting diodes offer the ability to test wavelength combinations to manipulate plant morphology and control plant stature (Folta and Childers, 2008; Stutte, 2009).

Light quality has been shown to have a significant effect on plant growth, development, and physiology (Brown et al., 1995; Sage, 1992; Smith, 1982). Previous studies have focused on the use of LEDs as solesource lighting in highly controlled and enclosed environments (Massa et al., 2008), as a SL source for intercanopy (Dueck et al., 2006; Hovi-Pekkanen et al., 2006; Trouwborst et al., 2010), or overhead (Dueck et al., 2012) lighting for greenhouse vegetable production, or propagation of ornamental cuttings (Currey and Lopez, 2013). Using LEDs requires determining the best light quality for each crop (Massa et al., 2008).

For example, when Zantedeschia jucunda K. Koch 'Black Magic' (calla lily) was grown in vitro under a total $P P F$ of $80 \mu \mathrm{mol} \cdot \mathrm{m}^{-2} \cdot \mathrm{s}^{-1}$ of varying proportions of red and blue light from LEDs, stem elongation, but not dry mass, could be manipulated. As blue light increased from 0 to $32 \mu \mathrm{mol} \cdot \mathrm{m}^{-2} \cdot \mathrm{s}^{-1}$ and red light was reduced from 80 to $48 \mu \mathrm{mol} \cdot \mathrm{m}^{-2} \cdot \mathrm{s}^{-1}$ $($ red:blue ratio $=1.5)$, stem elongation decreased from 10.5 to $8.5 \mathrm{~cm}$ (Jao et al., 2005). In a separate study, van Ieperen et al. (2012) grew Cucumis sativus L. 'Hoffman Giganta' (cucumber) in growth chambers under LEDs providing a $P P F$ of $100 \mu \mathrm{mol} \cdot \mathrm{m}^{-2} \cdot \mathrm{s}^{-1}$ of $100: 0$, $0: 100$, or $70: 30$ red:blue light over a $16-\mathrm{h}$ photoperiod. Petiole length of plants grown under 70:30 red:blue LEDs was reduced by $1.0 \mathrm{~cm}$, whereas stomatal density and net leaf photosynthesis increased by $248 \mathrm{~mm}^{-2}$ and $1.2 \mu \mathrm{mol} \mathrm{CO}_{2}$ per $\mathrm{m}^{-2} \cdot \mathrm{s}^{-1}$, respectively, compared with plants grown under monochromatic red light. Hernández and Kubota (2012) demonstrated the benefits of greenhouse SL on the growth and development of Solanum lycopersicum L. 'Komeett' (tomato) seedlings grown under solar DLIs of 8.9 to $19.4 \mathrm{~mol} \cdot \mathrm{m}^{-2} \cdot \mathrm{d}^{-1}$ and LED SL providing a $P P F$ of $56 \mu \mathrm{mol} \cdot \mathrm{m}^{-2} \cdot \mathrm{s}^{-1}$. However, there were no significant differences in shoot dry mass, leaf count, stem diameter, hypocotyl length, leaf area, or chlorophyll concentration among the different LED SL treatments providing red:blue $P P F$ ratios of 100:0, $96: 4$, or $84: 16$. Another study demonstrated no 
differences in productivity for greenhousegrown tomato 'Komeett' and 'Success' grown under overhead HPS lamps or intracanopy LEDs towers providing 95:5 red:blue light (Gómez et al., 2013).

To our knowledge, no previous studies have quantified the effects of narrow-spectra high-intensity LEDs as a SL source for annual bedding plant seedlings. The objectives of this study were to: 1) quantify the effects of SL from three LED sources of different light quality and HPS lamps on seedling growth, morphology, and quality; and 2) determine whether there were any residual effects of SL source on subsequent growth and development after transplant in a common environment.

\section{Materials and Methods}

Plant material, culture, and environmental conditions. Seeds of Antirrhinum majus L. 'Rocket Pink', Catharanthus roseus L. G. Don 'Titan Punch', Celosia argentea L. var. plumosa L. 'Fresh Look Gold', Impatiens walleriana Hook. f. 'Dazzler Blue Pearl', Pelargonium $\times$ hortorum L.H. Bailey 'Bullseye Scarlet', Petunia $\times$ hybrida Vilm.-Andr. 'Plush Blue', Salvia splendens Sellow ex Roem. \& Schult. 'Vista Red', Tagetes patula L. 'Bonanza Flame', and Viola $\times$ wittrockiana Gams. 'Mammoth Big Red' (Ball Horticulture, West Chicago, IL) were sown into 288cell $(5-\mathrm{mL}$ individual cell vol.) seed trays at a commercial greenhouse (Heartland Growers, Westfield, IN). Upon hypocotyl emergence, trays were placed in a glass-glazed greenhouse with an exhaust fan and evaporativepad cooling, radiant hot water heating, and retractable shade curtains controlled by an environmental control system (Maximizer Precision 10; Priva Computers Inc., Vineland Station, Ontario, Canada) at Purdue University, West Lafayette, IN (lat. $40^{\circ} \mathrm{N}$ ).

All species were placed under a $16-\mathrm{h}$ photoperiod with air temperatures of $21.2 \pm$ 1.7 and $21.7 \pm 2.0{ }^{\circ} \mathrm{C}$ for Celosia, Petunia, Impatiens, Tagetes, and Viola (Group I) and $20.9 \pm 0.96$ and $21.3 \pm 1.4{ }^{\circ} \mathrm{C}$ for Antirrhinum, Catharanthus, Pelargonium, and Salvia (Group II). Infrared temperature sensors (OS136; Omega Engineering, Inc., Stamford, CT) recorded seedling leaf temperatures every $30 \mathrm{~s}$ and averages were logged every 15 min by a data logger (Maximizer Precision 10). Amplified quantum sensors (LI-190; LICOR Biosciences, Lincoln, NE) measured solar $P P F$ every $30 \mathrm{~s}$ and the average of each sensor was logged every $15 \mathrm{~min}$ by a data logger (Model CR1000; Campbell Scientific, Inc., Logan, UT). Environmental data are reported in Table 1. Seedlings were irrigated with water-soluble fertilizer (Jack's LX 16N-0.94P-12.3K Plug Formula for High Alkalinity Water; J.R. Peters, Inc., Allentown, PA) providing (in $\mathrm{mg} \cdot \mathrm{L}^{-1}$ ): 100 nitrogen $(\mathrm{N})$, 10 phosphorus $(\mathrm{P}), 78$ potassium $(\mathrm{K}), 18$ calcium $(\mathrm{Ca}), 9.4$ magnesium $(\mathrm{Mg}), 0.10$ boron (B), 0.05 copper $(\mathrm{Cu}), 0.50$ iron $(\mathrm{Fe})$, 0.25 manganese $(\mathrm{Mn}), 0.05$ molybdenum (Mo), and 0.25 zinc ( $\mathrm{Zn})$.

Table 1. Average plant temperatures and daily light integral (DLI) under ambient solar daylight supplemented with $\approx 100 \mu \mathrm{mol} \cdot \mathrm{m}^{-2} \cdot \mathrm{s}^{-1}$ delivered from high-pressure sodium (HPS) lamps or lightemitting diodes with varying proportions of red (R) and blue (B) light from 0600 to $2000 \mathrm{HR}^{\mathrm{z}}$

\begin{tabular}{lcccc}
\hline $\begin{array}{l}\text { Treatment } \\
\text { initiation }\end{array}$ & $\begin{array}{c}\text { Supplemental light } \\
\text { source }\end{array}$ & $\begin{array}{c}\text { Supplemental light } \\
\left(\mu \mathrm{mol} \cdot \mathrm{m}^{-2} \cdot \mathrm{s}^{-1}\right)\end{array}$ & $\begin{array}{c}\text { Solar DLI } \\
\left(\mathrm{mol} \cdot \mathrm{m}^{-2} \cdot \mathrm{d}^{-1}\right)\end{array}$ & $\begin{array}{c}\text { Plant temp } \\
\left({ }^{\circ} \mathrm{C}\right)\end{array}$ \\
\hline 29 Mar. & HPS & $102.4 \pm 6.8$ & $7.1 \pm 2.1$ & $19.5 \pm 2.6$ \\
& 100R:0B & $98.4 \pm 1.2$ & $8.4 \pm 3.3$ & $18.2 \pm 3.1$ \\
& 85R:15B & $99.9 \pm 2.2$ & $7.7 \pm 1.5$ & $18.4 \pm 3.2$ \\
70R:30B & $99.2 \pm 3.1$ & $5.2 \pm 1.2$ & $17.7 \pm 2.5$ \\
24 May & HPS & $97.6 \pm 3.2$ & $6.8 \pm 2.0$ & $22.2 \pm 3.5$ \\
& 100R:0B & $101.5 \pm 3.6$ & $5.1 \pm 1.5$ & $21.0 \pm 2.7$ \\
& 85R:15B & $98.7 \pm 3.6$ & $5.6 \pm 1.5$ & $21.0 \pm 4.0$ \\
& 70R:30B & $98.4 \pm 5.7$ & $5.6 \pm 1.6$ & $20.7 \pm 3.1$ \\
& HPS & & & $19.8 \pm 2.8$ \\
18 Sept. & 100R:0B & $97.8 \pm 3.6$ & $2.6 \pm 1.1$ & $18.3 \pm 1.9$ \\
& 85R:15B & $97.2 \pm 2.1$ & $3.4 \pm 1.8$ & $18.0 \pm 2.1$ \\
& 70R:30B & $99.2 \pm 2.9$ & $2.8 \pm 1.2$ & $18.4 \pm 2.4$ \\
& HPS & $93.8 \pm 2.4$ & $3.0 \pm 1.7$ & $20.7 \pm 2.4$ \\
& 100R:0B & & & $18.6 \pm 1.9$ \\
& 85R:15B & $93.1 \pm 3.3$ & $2.7 \pm 1.9$ & $19.0 \pm 2.1$ \\
& 70R:30B & $98.6 \pm 3.9$ & $2.4 \pm 1.5$ & $18.4 \pm 2.4$ \\
\hline
\end{tabular}

${ }^{\mathrm{z} C e l o s i a, ~ P e t u n i a, ~ I m p a t i e n s, ~ T a g e t e s, ~ a n d ~ V i o l a ~ w e r e ~ p l a c e d ~ u n d e r ~ t r e a t m e n t s ~ o n ~} 29$ Mar. and 24 May and Antirrhinum, Catharanthus, Pelargonium, and Salvia were placed under treatments on 18 Sept. and 23 Oct.

Supplemental lighting treatments. Seedlings were grown under ambient solar light supplemented with $100 \mu \mathrm{mol} \cdot \mathrm{m}^{-2} \cdot \mathrm{s}^{-1}$ $P P F$ at plant height [as measured with a spectroradiometer (PS-100; Apogee Instruments, Logan, UT)] from 0600 to $2200 \mathrm{HR}$, which provided a supplemental DLI of $5.8 \mathrm{~mol} \cdot \mathrm{m}^{-2} \cdot \mathrm{d}^{-1}$. Supplemental light was delivered from a 150-W HPS lamp (PL2000; P.L. Lights, Beamsville, Ontario, Canada) or one of three LED arrays (Philips GreenPower LED research module; Koninklijke Philips Electronics N.V., The Netherlands). Each group of LED arrays was spaced on $6.3-\mathrm{cm}$ centers and consisted of $48.5 \mathrm{~cm}$-long and $3.3 \mathrm{~cm}$-wide square aluminum bars containing five 660- or 470-nm LEDs. The 100:0, $85: 15$, and $70: 30$ red:blue ratio treatments contained 20 red bars, 18 red and four blue bars, and 15 red and seven blue bars alternating, respectively. Spectral scans of SL were taken at night at the beginning and end of each replication with a spectroradiometer (PS-100; Apogee Instruments, Inc.). Spectral quality of SL sources is shown in Figure 1. Electrical use $\left(\mathrm{kWh} \cdot \mathrm{d}^{-1}\right)$ for both HPS lamps and LED lights was measured using an electrical meter (P440 Kill A Watt; P3 International, New York, NY).

Finishing culture and environment. Twentyeight days after the placement of trays under SL sources, 10 randomly selected seedlings from each tray were transplanted into $10.2-\mathrm{cm}$ (460-mL) containers (Dillen Products, Middlefield, $\mathrm{OH}$ ) filled with a soilless medium comprised of (by vol.) $65 \%$ peat, $20 \%$ perlite, and $15 \%$ vermiculite (Fafard 2; Fafard, Inc., Agawam, MA). Plants were placed in a common finish environment with a 16-h photoperiod of ambient light supplemented with a $P P F$ of $70 \mu \mathrm{mol} \cdot \mathrm{m}^{-2} \cdot \mathrm{s}^{-1}$ from HPS lamps to provide a target DLI of $\approx 10$ to $12 \mathrm{~mol} \cdot \mathrm{m}^{-2} \cdot \mathrm{d}^{-1}$. Air temperatures in the finishing environment were $22.7 \pm 2.2$ and $22.1 \pm 3.2{ }^{\circ} \mathrm{C}$ (Group I) and $21.1 \pm 0.6$ and $21.9 \pm 1.8^{\circ} \mathrm{C}$ (Group II). Plants were irrigated as necessary with acidified water supplemented with a combination of two water-soluble fertilizers (3:1 mixture of $15 \mathrm{~N}-2.2 \mathrm{P}-12.5 \mathrm{~K}$ and $21 \mathrm{~N}-2.2 \mathrm{P}-16.6 \mathrm{~K}$, respectively; Everris, Marysville, $\mathrm{OH}$ ) to provide the following $\left(\mathrm{mg} \cdot \mathrm{L}^{-1}\right): 200 \mathrm{~N}, 26 \mathrm{P}$, $163 \mathrm{~K}, 50 \mathrm{Ca}, 20 \mathrm{Mg}, 1.0 \mathrm{Fe}, 0.5 \mathrm{Mn}$ and $\mathrm{Zn}$, $0.24 \mathrm{Cu}$ and $\mathrm{B}$, and $0.1 \mathrm{Mo}$.

Data collection and calculations. At 14, 21 , and $28 \mathrm{~d}$ after initiating SL treatments, 25 plants of each species were randomly harvested and measured for pullability (the number of seedlings that can be pulled from the tray with roots and media intact). The collective roots and shoots of the 25 plants were washed and placed in a drying oven at $70{ }^{\circ} \mathrm{C}$. After $4 \mathrm{~d}$, roots and shoots were weighed to determine collective root dry mass (RDM) and shoot dry mass (SDM), respectively.

At $28 \mathrm{~d}$ after initiating SL treatments, 10 plants from each species were randomly selected and measured for stem length (measured from the base of the hypocotyl to the shoot apical meristem) and stem caliper above the lowest leaf with a digital caliper (digiMax; Wiha, Schonach, Germany). Relative chlorophyll content was measured with a SPAD meter (SPAD-502; Konica Minolta Sensing, Inc., Osaka, Japan). After nondestructive measurements were recorded, roots and shoots of all selected seedlings were washed and separated, placed in a drying oven at $70{ }^{\circ} \mathrm{C}$ for at least $4 \mathrm{~d}$, and RDM and SDM were recorded. The sturdiness quotient (SQ) was calculated as stem caliper divided by stem length. The QI, an objective, integrated, and quantitative measurement of quality, was calculated as the [total dry mass $\times$ (shoot:root ratio + sturdiness quotient)] (Currey et al., 2013).

Transplants in the finish environment were monitored daily after planting. When 


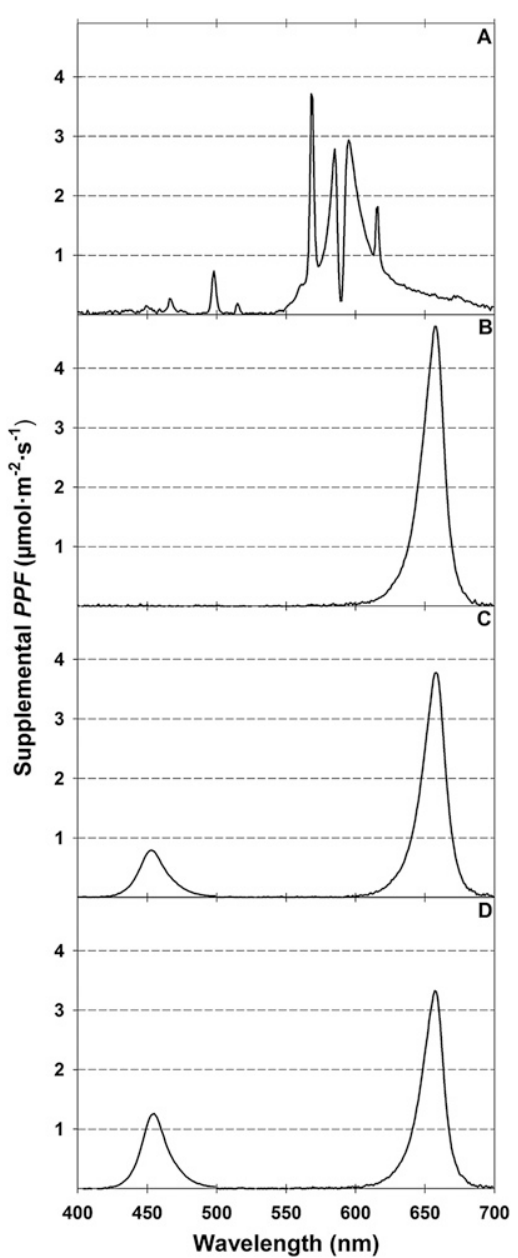

Fig. 1. (A - D) Spectral quality of $100 \mu \mathrm{mol} \cdot \mathrm{m}^{-2} \cdot \mathrm{s}^{-1}$ delivered from high-pressure sodium (HPS) lamps (A) or light-emitting diodes (LEDs) with (\%) 100:0 (B), 85:15 (C), 70:30 (D) red:blue light.

the first flower opened, the date, node number beneath the first open flower, and plant height from the surface of the medium to the top of the plant were recorded. Time to flower (TTF) was calculated as the time from transplant into the finish environment to the first flower opening.

Statistical analysis. The experiment used a complete block design replicated twice in time for each of the nine species. There were 10 samples (individual plants) per species per SL treatment for seedling and finish data. Data were analyzed using SAS (SAS 9.3; SAS Institute Inc., Cary, NC) mixed model procedure (PROC MIXED) for analysis of variance.

\section{Results}

Height. Height of all species with the exception of Pelargonium was significantly shorter under LED SL treatments (Fig. 2A-C). For example, height of Catharanthus, Celosia, Impatiens, Petunia, Salvia, Tagetes, and Viola was $31 \%, 29 \%, 31 \%, 55 \%, 20 \%, 9 \%$, and $35 \%$ shorter for seedlings grown under the 85:15 red:blue LEDs compared with those grown under HPS lamps, respectively. Antirrhinum seedlings under 70:30 red:blue LEDs were $9 \%$ shorter than those grown under HPS lamps.

Stem caliper. Stem caliper of Antirrhinum, Pelargonium, and Tagetes seedlings was significantly larger under LED treatments (Fig. 2D-F). For example, stem caliper of Antirrhinum, Pelargonium, and Tagetes was $16 \%, 8 \%$, and $13 \%$ larger, respectively, for seedlings grown under the 85:15 red:blue LEDs compared with seedlings grown under HPS lamps. Under 70:30 red:blue LEDs, stem caliper of Celosia and Viola seedlings was significantly smaller than under the other SL treatments. Stem caliper of Celosia grown under 70:30 red:blue LEDs was 9\% smaller than plants grown under HPS lamps. Stem caliper of Catharanthus, Impatiens, Petunia, and Salvia was not significantly influenced by SL treatments.

Root dry mass. Root dry mass of Celosia and Impatiens was highest under the HPS lamps and 100:0 red:blue LEDs (Fig. 2G-I). However, RDM of Petunia, Salvia, and Viola was lowest under the 70:30 red:blue LEDs. For example, RDM of Salvia was 36\% lower for plants grown under 70:30 red:blue LEDs than under HPS lamps. There were no significant differences in RDM between HPS and LED SL treatments for Antirrhinum, Catharanthus, Pelargonium, and Tagetes.

Shoot dry mass. Shoot dry mass of Celosia was highest under the HPS and 100:0 red:blue LEDs (Fig. 2J-L). The SDM of Impatiens, Petunia, Salvia, and Viola was lowest under the 70:30 red:blue LEDs. For example, SDM of Impatiens, Petunia, Salvia, and Viola was $18 \%, 25 \%, 24 \%$, and $40 \%$ lower under 70:30 red:blue LEDs, respectively, than under HPS lamps. However, there were no significant differences in SDM of Antirrhinum, Catharanthus, Pelargonium, and Tagetes between HPS and LED SL treatments.

Sturdiness quotient. Sturdiness quotient of Antirrhinum, Catharanthus, Impatiens, Pelargonium, Petunia, Tagetes, and Viola was highest under LED SL treatments (Fig. $3 \mathrm{~A}-\mathrm{C}$ ). For example, SQ of Antirrhinum and Pelargonium was $22 \%$ and $23 \%$ higher under the 70:30 red:blue LEDs when compared with HPS lamps. Sturdiness quotient of Impatiens was 54\% higher under 85:15 red:blue LEDs than plants grown under HPS lamps. For Celosia and Salvia, SQ was not significantly different between HPS and LED SL treatments.

Root:shoot ratio. Root:shoot ratio was highest under LED SL treatments for Catharanthus, Impatiens, Petunia, Salvia, and Viola (Fig. 3D-F). For example, root:shoot ratio of Catharanthus and Impatiens was $27 \%$ and $23 \%$ higher under the 70:30 red:blue LEDs and 100:0 red:blue LEDs, respectively, than under HPS lamps. However, root:shoot ratio was lowest under the 70:30 red:blue LEDs for Celosia and Tagetes. No significant differences between HPS and LED SL treatments were found for root:shoot ratio of Antirrhinum and Pelargonium.
Quality index. Under LED SL treatments, QI of Petunia, Salvia, and Viola was highest compared with HPS lamps (Fig. 3G-I). For example, QI of Petunia, Salvia, and Viola was $68 \%, 30 \%$, and $33 \%$ higher under $85: 15$, 70:30, and 100:0 red:blue LEDs, respectively, than under HPS lamps. Quality index of Celosia was highest under the HPS lamps. Quality index was not significantly influenced by SL treatment for Antirrhinum, Catharanthus, Impatiens, Pelargonium, and Tagetes.

Relative chlorophyll content. Relative chlorophyll content was highest under LED SL treatments for Antirrhinum, Pelargonium, and Salvia (Fig. 3J-L). For example, relative chlorophyll content was $21 \%$ and $15 \%$ higher, respectively, for Pelargonium and Salvia seedlings grown under 70:30 red:blue LEDs than under HPS lamps. However, relative chlorophyll content of Catharanthus was not significantly different under HPS or LED SL treatments.

Height at flower. Catharanthus and Pelargonium were shorter at flower when grown under HPS lamps compared with LED SL treatments (Fig. 4A-C). For example, Pelargonium was $42 \%$ shorter at the time of flower when grown under HPS lamps compared with 100:0 red:blue LEDs. However, height at the time of first open flower was not significantly different for Antirrhinum, Celosia, Impatiens, Petunia, Salvia, Tagetes, or Viola grown under HPS or LED SL treatments.

Nodes below open flower. Celosia had more nodes below the first open flower when grown under 70:30 red:blue LEDs compared with other SL treatments; however, Impatiens and Petunia had fewer nodes below the first open flower when grown under 70:30 red:blue LEDs compared with other SL treatments (Fig. 4D-F). Petunia, for example, had two fewer nodes below the first open flower for plants grown under 70:30 red:blue LEDs compared with HPS lamps. No significant difference in the number of nodes below the first open flower was observed for Antirrhinum, Catharanthus, Pelargonium, Salvia, Tagetes, and Viola grown under HPS or LED SL treatments.

Time to flower. TTF for Pelargonium occurred $20 \mathrm{~d}$ earlier for plants grown under 70:30 red:blue LEDs compared with plants grown under 100:0 red:blue LEDs (Fig. 4G-I). TTF of Celosia, Impatiens, Salvia, and Tagetes was generally slower for plants grown under LEDs compared with HPS lamps. However, TTF was not significantly different for plants grown under HPS or LED SL treatments for Antirrhinum, Catharanthus, Petunia, and Viola.

\section{Discussion}

A high-quality seedling is one that is compact, fully rooted with a large stem caliper and high RDM. Compact seedlings with a large stem caliper and RDM are less likely to be damaged during shipping and transplant (Pramuk and Runkle, 2005b). The QI is a useful tool to assess young plant quality by 


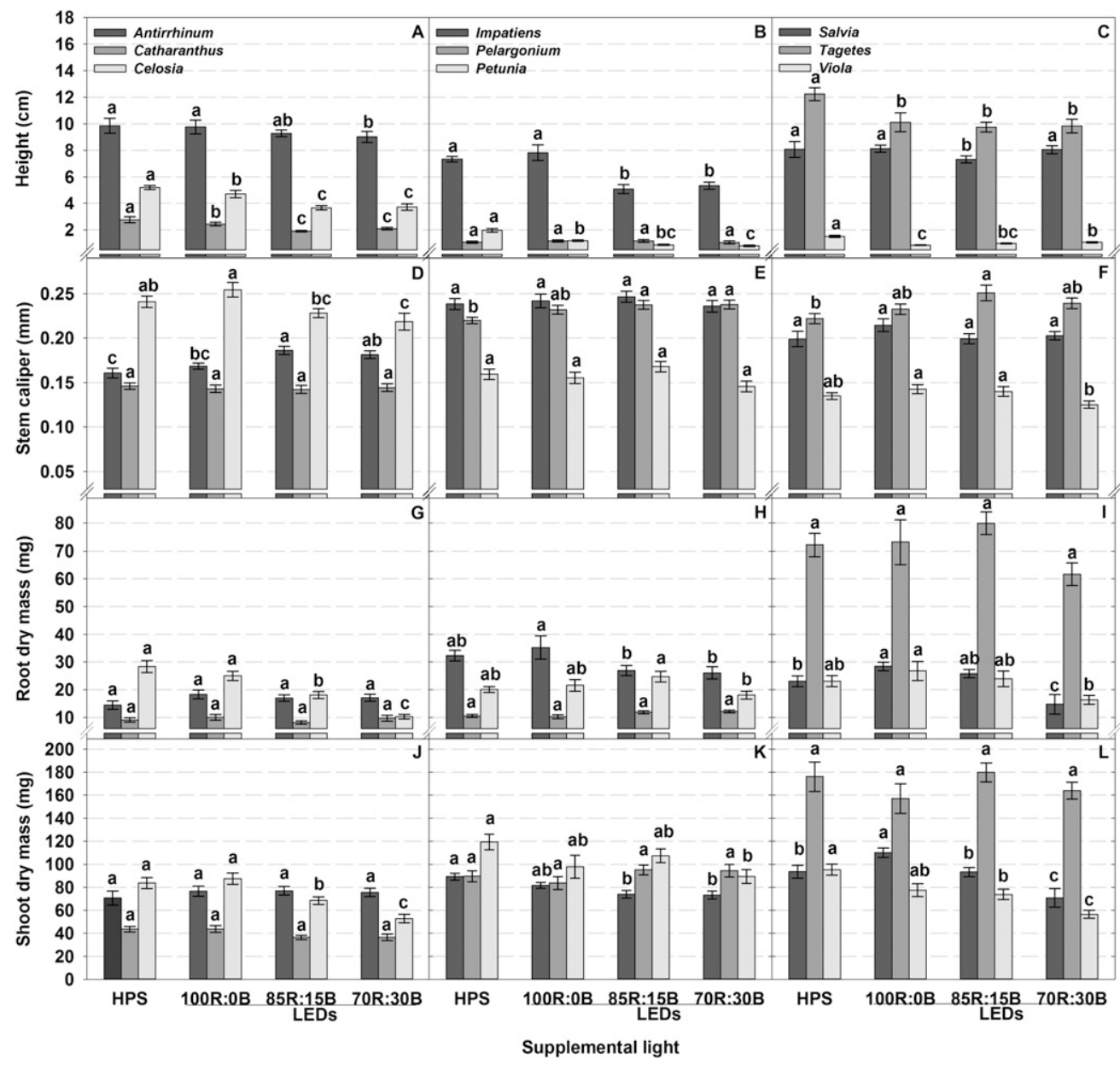

Fig. 2. (A-L) Effect of $100 \mu \mathrm{mol} \cdot \mathrm{m}^{-2} \cdot \mathrm{s}^{-1}$ of supplemental light delivered from high-pressure sodium (HPS) lamps or light-emitting diodes (LEDs) with varying proportions of red:blue light during seedling production on height, stem caliper, root dry mass, and shoot dry mass for Antirrhinum, Catharanthus, Celosia, Impatiens, Pelargonium, Petunia, Salvia, Tagetes, and Viola after 28 d. Different lower-case letters across supplemental light source within a species are significantly different by Tukey's honestly significant difference (HSD) test at $P \leq 0.05$. Each bar represents a mean of 10 plants, and error bars represent sES of the mean.

integrating the morphological parameters that contribute to the perceived quality of plugs and liners (Currey et al., 2013). In our study, parameters of seedling quality using the QI were similar to HPS lamps or higher for Antirrhinum, Catharanthus, Impatiens, Petunia, Pelargonium, Salvia, Tagetes, and Viola grown under LED SL for $28 \mathrm{~d}$. Celosia was the only species in which the QI was lowest under LED treatments providing blue light.

Antirrhinum, Catharanthus, Impatiens, Pelargonium, Petunia, and Tagetes grown under the 85:15 and 70:30 red:blue LEDs were generally more compact with a larger stem caliper, higher SQ, and higher relative chlorophyll content than plants grown under HPS lamps. The RDM of these species was statistically similar to those produced under HPS lamps. However, SDM of Impatiens and Petunia was lower when seedlings were grown under LEDs containing blue light. Several studies have highlighted the importance of blue light when used as a sole source or SL. For example, the number of tillers in Triticum aestivum L. 'USU-Super Dwarf' (wheat) was similar under 90:10 red:blue light as plants grown under white light. Additionally,
$15 \mathrm{~d}$ after transplant, SDM increased from 0.85 to $1.42 \mathrm{~g}$ and photosynthesis increased from 5.3 to $8.3 \mu \mathrm{mol} \mathrm{CO}_{2}$ per $\mathrm{m}^{-2} \cdot \mathrm{s}^{-1}$ as the proportion of blue light supplementing red light increased from $1 \%$ to $10 \%$ (Goins et al., 1997). Dueck et al. (2012) demonstrated that leaf thickness of 'Sunstream' tomato plants increased by $12 \%$ when grown under LEDs with a ratio of $88: 12$ red:blue light compared with those grown under HPS lamps. When Arabidopsis thaliana L. plants were grown under 100:0 red:blue LEDs, they exhibited abnormal leaf morphology, delayed flowering, and reduced seed production. However, 90:10 red:blue fluorescent light resulted in plants that had a similar TTF and increased germination rate compared with plants grown under white fluorescent light (Goins et al., 1998). When cuttings of Impatiens hawkeri W. Bull 'Celebrette Frost' and Pelargonium $\times$ hortorum L.H. Bailey 'Designer Bright Red' were grown under SL from HPS lamps, 100:0, $85: 15$, or $70: 30$ red:blue LEDs, no significant differences in growth and morphology were observed. However, leaf dry mass, root dry mass, root mass ratio, and root:shoot ratio increased $15 \%, 36 \%, 17 \%$, and $24 \%$, respectively, for petunia 'Suncatcher Midnight
Blue' cuttings grown under 70:30 red:blue LEDs compared with HPS lamps (Currey and Lopez, 2013).

Our results show that relative chlorophyll content increased as the amount of blue light increased for some species. XiaoYing et al. (2011) focused on the cellular changes that result from using different color wavelength LEDs on tomato. Plants grown under any LED treatment with blue light had significantly thicker leaves and longer palisade cells than plants grown in other LED treatments. For example, leaf thickness and palisade cell length were 23.1 and $2.5 \mu \mathrm{m}$ under 100:0 red:blue LEDs but increased to 35.9 and $14.4 \mu \mathrm{m}$ under 50:50 red:blue LEDs, a 55.4 and $476.0 \%$ increase, respectively. Additionally, chloroplasts were more developed and stomata density increased under the red: blue LEDs compared with the monochromatic red LEDs. Additionally, enhanced net photosynthesis was measured for leaves irradiated with blue LEDs. Similarly, our study demonstrated that relative chlorophyll content increased by $21 \%$ and $15 \%$ for Pelargonium and Salvia grown under 70:30 red: blue LEDs compared with HPS lamps, respectively. 


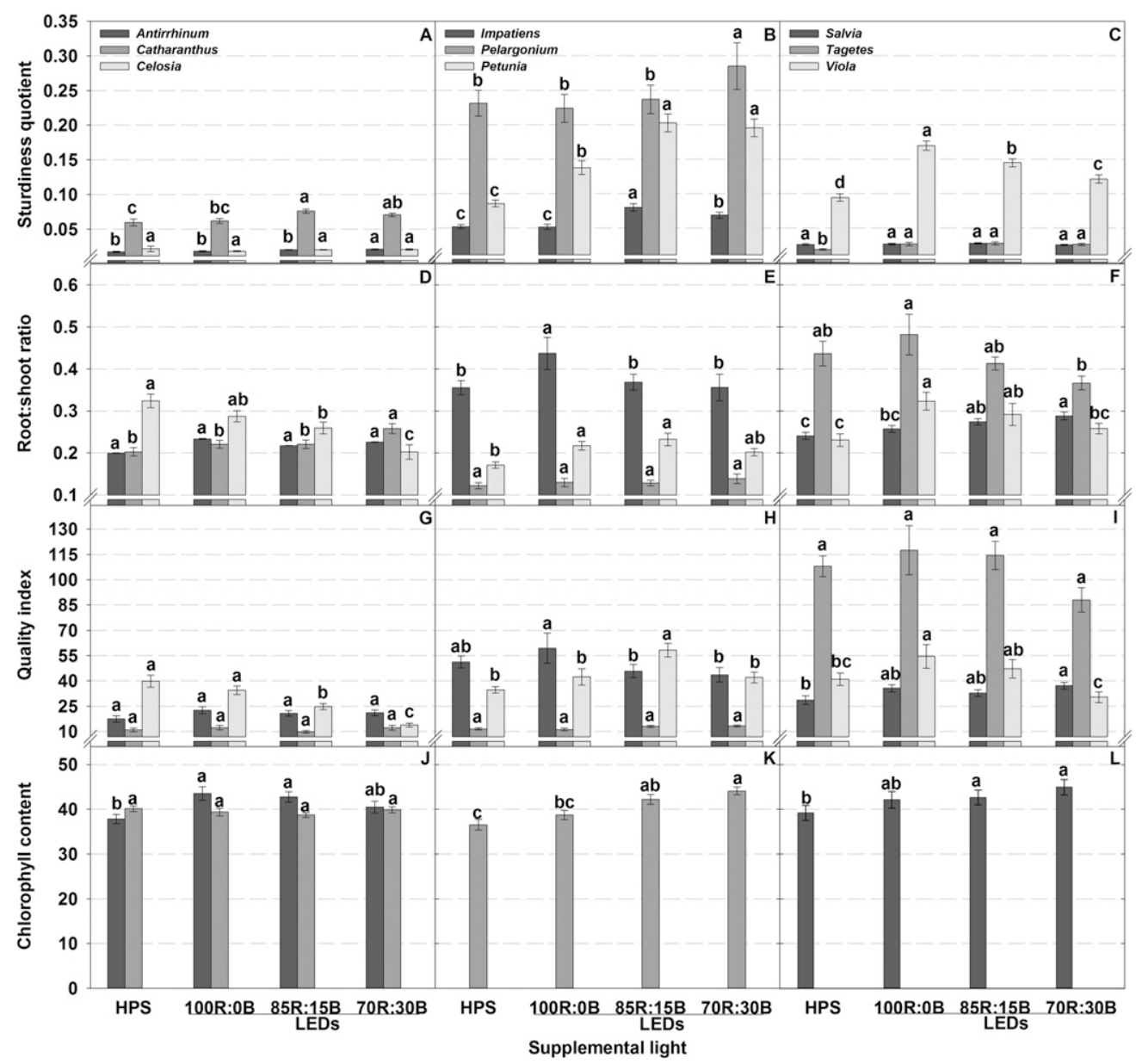

Fig. 3. (A-L) Effect of $100 \mu \mathrm{mol} \cdot \mathrm{m}^{-2} \cdot \mathrm{s}^{-1}$ of supplemental light delivered from high-pressure sodium (HPS) lamps or light-emitting diodes (LEDs) with varying proportions of red:blue light during seedling production on sturdiness quotient, root:shoot ratio, quality index, and relative chlorophyll content for Antirrhinum, Catharanthus, Celosia, Impatiens, Pelargonium, Petunia, Salvia, Tagetes, and Viola on 28 d. Different lower-case letters across supplemental light source within a species are significantly different by Tukey's honestly significant difference (HSD) test at $P \leq 0.05$. Each bar represents a mean of 10 plants, and error bars represent SES of the mean.

TTF of Celosia, Impatiens, Salvia, and Tagetes was reduced for plants grown under the HPS lamps compared with most of the LED treatments. We postulate that hastened flowering could be attributed to increased seedling temperature of $\approx 1$ to $2{ }^{\circ} \mathrm{C}$ under HPS lamps (Table 1). High-pressure sodium lamps are rated to be $25 \%$ to $30 \%$ efficient at converting electrical energy to light; the other $70 \%$ to $75 \%$ is radiated as heat energy (Spaargaren, 2001). Celosia is the only species considered cold-sensitive and must be grown under higher temperatures because it has an estimated base temperature of $10^{\circ} \mathrm{C}$ (Runkle and Blanchard, 2011). Pramuk and Runkle (2005a) demonstrated the influence of temperature and use of SL from HPS lamps on development of Celosia. TTF was quadratically related to DLI and temperature; as temperature increased up to $\approx 25^{\circ} \mathrm{C}$ and DLI increased from 5 to $15 \mathrm{~mol} \cdot \mathrm{m}^{-2} \cdot \mathrm{d}^{-1}$, TTF decreased. However, further increase in DLI had no significant effect on TTF. Additionally, as temperature increased from 15 to $28^{\circ} \mathrm{C}$ under an average DLI of $8 \mathrm{~mol} \cdot \mathrm{m}^{-2} \cdot \mathrm{d}^{-1}$, plant height increased from 17 to $27 \mathrm{~cm}$ (37\%). When HPS lamps were used to increase the DLI from 5 to $25 \mathrm{~mol} \cdot \mathrm{m}^{-2} \cdot \mathrm{d}^{-1}$, shoot dry mass doubled from 3.6 to $7.2 \mathrm{~g}$ for plants grown under $25^{\circ} \mathrm{C}$.

Previous studies with bedding plants have demonstrated that increased DLI during the young plant stage results in earlier flowering during the finish stage (Hutchinson et al., 2012; Lopez and Runkle, 2008; Oh et al., 2010). For example, increasing DLI with SL later in the plug stage for petunia 'Madness Red' and pansy 'Delta Premium Yellow' resulted in earlier flowering but lower dry mass and bud number than in the first one- or two-thirds of production. Supplemental lighting during the entire plug stage and last two-thirds of the plug stage reduced TTF by 4.8 and $4.7 \mathrm{~d}$ in petunia and 4.7 and $5.7 \mathrm{~d}$ in pansy, respectively, when compared with the photoperiodic low light control (Oh et al., 2010). Similarly, as DLI increased from 1.2 to $12.3 \mathrm{~mol} \cdot \mathrm{m}^{-2} \cdot \mathrm{d}^{-1}$, TTF decreased by 23 and $19 \mathrm{~d}$ for Angelonia angustifolia 'AngelMist White Cloud' and Osteospermum ecklonis 'Voltage Yellow', respectively (Hutchinson et al., 2012). Although we did not have a treatment without supplemental lighting, we provided the same DLI with all our SL treatments and determined that TTF was similar for Antirrhinum, Catharanthus, Petunia, and Viola grown under the HPS lamps and LEDs.

Although energy consumption and efficiency of SL sources were not a primary focus of this study, they do warrant mentioning. The daily energy consumption for the HPS, 100:0, 85:15, and 70:30 red:blue was as follows: $3.01,1.23,1.35$, and $1.56 \mathrm{kWh} \cdot \mathrm{d}^{-1}$, respectively. Energy consumption from the LEDs to light five plugs trays decreased by $59.1 \%, 55.1 \%$, and $48.2 \%$ for the $100: 0$, $85: 15$, and 70:30 red:blue LED arrays, respectively, compared with one 150-W HPS lamp. The LED arrays used in this study were passively cooled and therefore did not use any additional energy for active cooling as compared with the LEDs used by Currey and Lopez (2013). As a result of using passively cooled LEDs, ambient solar radiation was blocked by $\approx 50 \%$ as a result of the increased size of the fixtures. Currey and Lopez (2013) found that using actively cooled LEDs with forced-air cooling consumed 3.29, 3.43, and $4.06 \mathrm{kWh} \cdot \mathrm{d}^{-1}$ for $100: 0,85: 15$, and $70: 30$ red:blue LEDs, respectively, compared with HPS lamps that used $3.01 \mathrm{kWh} \cdot \mathrm{d}^{-1}$. They calculated the energy consumption of the fans used to cool the arrays and reported that 


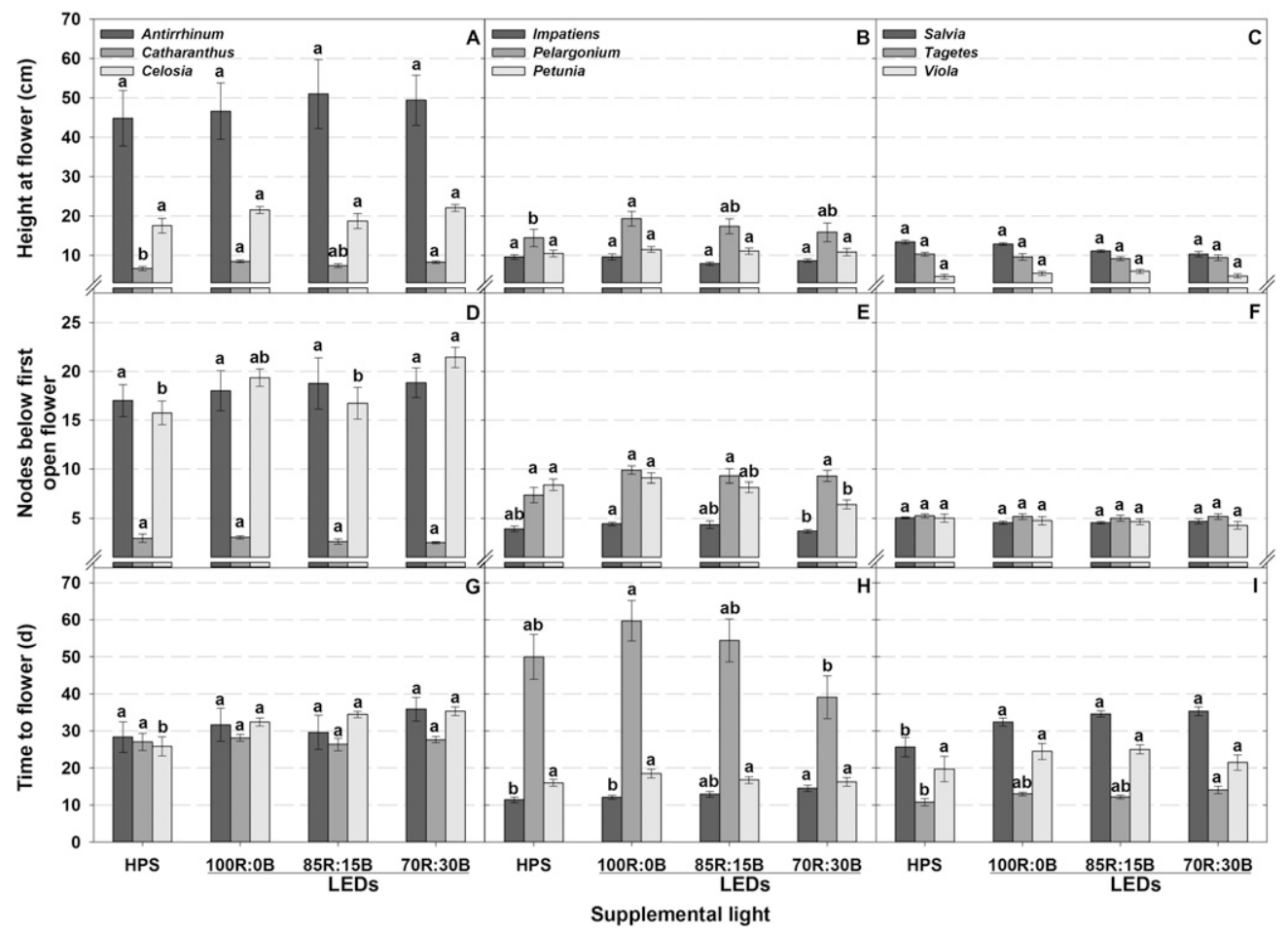

Fig. 4. (A-I) Effect of $100 \mu \mathrm{mol} \cdot \mathrm{m}^{-2} \cdot \mathrm{s}^{-1}$ of supplemental light delivered from high-pressure sodium (HPS) lamps or light-emitting diodes (LEDs) with varying proportions of red:blue light during seedling production on finish height, number of nodes below the flower, and time to flower for Antirrhinum, Catharanthus, Celosia, Impatiens, Pelargonium, Petunia, Salvia, Tagetes, and Viola. Different lower-case letters across supplemental light source within a species are significantly different by Tukey's honestly significant difference (HSD) test at $P \leq 0.05$. Each bar represents a mean of 10 plants, and error bars represent sES of the mean.

they accounted for $37 \%$ to $45 \%$ of the energy consumed by the LED arrays. Without fans, the LED arrays showed a $15 \%$ to $40 \%$ energy reduction compared with the HPS lamps. The need for heat dissipation without significant shading poses challenges to developing LED arrays for greenhouse use, because the materials used to construct LED arrays are important factors for thermal dissipation (Bourget, 2008; Christensen and Graham, 2009).

\section{Conclusions}

The QIs of the majority of species tested in this study were similar or higher for plants grown under SL from LEDs containing both red and blue light compared with those seedlings grown under HPS lamps. For species in which TTF was delayed when seedlings were grown under LEDs, the delay was not commercially significant with the exception of Celosia and Salvia. Therefore, a light ratio of 85:15 red:blue light could be a good combination for greenhouse LED SL of bedding plant plugs. However, it is also important to remember that although blue LEDs have a higher electrical conversion efficiency compared with red LEDs, blue light is a higher energy light, which increases energy consumption as higher proportions of blue are used. Therefore, further research is necessary to determine if lower amounts of blue light can yield adequate plant responses. Our results indicate that providing SL from LEDs or HPS lamps has a positive influence on seedling RDM, height, and stem caliper leading to high-quality bedding plant seedlings when solar light is limiting.

\section{Literature Cited}

Armitage, A.M. and M.P. Kaczperski. 1994. Traditional versus plug production, p. 113-126. In: Holcomb, E.J. (ed.). Bedding plants IV. Ball Publishing, Batavia, IL.

Barta, D.J., T.W. Tibbitts, R.J. Bula, and R.C. Morrow. 1992. Evaluation of light-emitting diode characteristics for a space-based plant irradiation source. Adv. Space Res. 12:141-149.

Bourget, C.M. 2008. An introduction to lightemitting diodes. HortScience 43:1944-1946.

Brown, C.S., A.C. Schuerger, and J.C. Sager. 1995. Growth and photomorphogenesis of pepper plants under red light-emitting diodes with supplemental blue or far-red lighting. J. Amer. Soc. Hort. Sci. 120:808-813.

Bula, R.J., R.C. Morrow, T.W. Tibbitts, D.J. Barta, R.W. Ignatius, and T.S. Martin. 1991. Light emitting diodes as a radiation source for plants. HortScience 26:203-205.

Christensen, A. and S. Graham. 2009. Thermal effects in packaging high power light emitting diode arrays. Appl. Therm. Eng. 29:364 371.

Currey, C.J., V.A. Hutchinson, and R.G. Lopez. 2012. Growth, morphology, and quality of rooted cuttings of several herbaceous annual bedding plants are influenced by photosynthetic daily light integral during root development. HortScience 47:25-30.

Currey, C.J. and R.G. Lopez. 2013. Cuttings of Impatiens, Pelargonium, and Petunia propagated under light-emitting diodes and high-pressure sodium lamps have comparable growth, morphology, gas exchange, and post-transplant performance. HortScience 48:428-434.
Currey, C.J., A.P. Torres, R.G. Lopez, and D.F. Jacobs. 2013. The quality index - a new tool for integrating quantitative measurements to assess quality of young floriculture plants. Acta Hort. 1000:385-391.

Dueck, T.A., C. Grashoff, G. Broekhuijsen, and L.F.M. Marcelis. 2006. Efficiency of light energy used by leaves situated in different levels of sweet pepper canopy. Acta Hort. 711:201-206.

Dueck, T.A., J. Janse, B.A. Eveleens, F.L.K Kempkes, and L.F.M. Marcelis. 2012. Growth of tomatoes under hybrid LED and HPS lighting. Acta Hort. 952:335-342.

Faust, J.E., V. Holcombe, N.C. Rajapakse, and D.R. Layne. 2005. The effect of daily light integral on bedding plant growth and flowering. HortScience 40:645-649.

Fisher, P. and A.J. Both. 2004. Supplemental lighting technology and costs, p. 43-46. In: Fisher, P. and E. Runkle (eds.). Lighting up profits: Understanding greenhouse lighting. Meister Media Worldwide, Willoughby, $\mathrm{OH}$.

Folta, K.M. and K.S. Childers. 2008. Light as a growth regulator: Controlling plant biology with narrow-band width solid-state lighting systems. HortScience 43:1957-1964.

Goins, G.D., N.C. Yorio, M.M. Sanwo, and C.S. Brown. 1997. Photomorphogenesis, photosynthesis, and seed yield of wheat plants grown under red light-emitting diodes (LEDs) with and without supplemental blue lighting. J. Expt. Bot. 48:1407-1413.

Goins, G.D., N.C. Yorio, M.M. Sanwo-Lewandowski, and C.S. Brown. 1998. Life cycle experiments with Arabidopsis grown under red light-emitting diodes (LEDs). Life Support and Biosphere Science: Intl. J. Earth Space 5:143-149.

Gómez, C., R.C. Morrow, C.M. Bourget, G.D. Massa, and C.A. Mitchell. 2013. Comparison 
of intracanopy light-emitting diode towers and overhead high-pressure sodium lamps for supplemental lighting of greenhouse-grown tomatoes. HortTechnology 23:93-98.

Hernández, R. and C. Kubota. 2012. Tomato seedling growth and morphological responses to supplemental LED lighting red:blue ratios under varied daily solar light integrals. Acta Hort. 956:187-194.

Hovi-Pekkanen, T., J. Näkkilä, and R. Tahvonen. 2006. Increasing productivity of sweet pepper with interlighting. Acta Hort. 711:165-170.

Hutchinson, V.A., C.J. Currey, and R.G. Lopez. 2012. Photosynthetic daily light integral during root development influences subsequent growth and development of several herbaceous annual bedding plants. HortScience 47:856-860.

Jao, R., C. Lai, W. Fang, and S. Chang. 2005. Effects of red light on the growth of Zantedeschia plantlets in vitro and tuber formation using light-emitting diodes. HortScience 40:436438.

Kuehny, J.S., A. Painter, and P.C. Branch. 2001. Plug source and growth retardants affect finish size of bedding plants. HortScience 36:321-323.

Lopez, R.G. and E.S. Runkle. 2008. Photosynthetic daily light integral during propagation influences rooting and growth of cuttings and subsequent development of new guinea impatiens and petunia. HortScience 43:2052-2059.

Massa, G.D., H. Kim, R.M. Wheeler, and C.A. Mitchell. 2008. Plant productivity in response to LED lighting. HortScience 43:1951-1956.
Nelson, P.V. 2012. Greenhouse operation and management. 7th Ed. Pearson Prentice Hall, Upper Saddle River, NJ.

Oh, W., E.S. Runkle, and R.M. Warner. 2010. Timing and duration of supplemental lighting during the seeding stage influence quality and flowering in Petunia and Pansy. HortScience 45:1332-1337.

Philips Lumileds. 2011. Luxeon Rebel and Luxeon Rebel ES color portfolio technical datasheet DS68. 5 Jan. 2014. <http://www1.futureelectronics. com/doc/PHILIPS\%20LUMILEDS/LXML-PL010040.pdf $>$.

Pramuk, L.A. and E.S. Runkle. 2005a. Modeling growth and development of Celosia and Impatiens in response to temperature and photosynthetic daily light integral. J. Amer. Soc. Sci. 130:813-818.

Pramuk, L.A. and E.S. Runkle. 2005b. Photosynthetic daily light integral during the seedling stage influences subsequent growth and flowering of Celosia, Impatiens, Salvia, Tagetes, and Viola. HortScience 40:1336-1339.

Runkle, E.S. and M. Blanchard. 2011. Implications of base temperature. 27 June 2013. <http:// www.gpnmag.com/sites/default/files/gpn0111_ TechnicallySpeaking.pdf $>$.

Sage, L.C. 1992. Shade avoidance, p. 371-395. In: Sage, L.C. (ed.). Pigment of the imagination: A history of phytochrome research. Academic Press, San Diego, CA.

Sherrard, T. 2003. Supplemental lighting, p. $137-$ 140. In: Beytes, C. (ed.). Ball redbook. 17th
Ed., Vol 1: Greenhouses and equipment. Ball Publishing, Batavia, IL.

Smith, H. 1982. Light quality, photoreception, and plant strategy. Annu. Rev. Plant Physiol. 33:481518.

Spaargaren, I.J.J. 2001. Supplemental lighting for greenhouse crops. 2nd Ed. P.L. Systems, Inc., Beamsville, Ontario, Canada.

Stutte, G.W. 2009. Light-emitting diodes for manipulating the phytochrome apparatus. HortScience 44:231-234.

Trouwborst, G., J. Oosterkamp, S.W. Hogewoning, J. Harbinson, and W.V. Ieperen. 2010. The responses of light interception, photosynthesis and fruit yield of cucumber to LED-lighting within the canopy. Physiol. Plant. 138:289300 .

U.S. Dept. of Agriculture. 2013. Floriculture crops 2012 summary. Nat. Agr. Sta. Service, Washington, DC. 25 Nov. 2013. <http://usda01.library. cornell.edu/usda/current/FlorCrop/FlorCrop-0425-2013.pdf $>$.

van Ieperen, W., A. Savvides, and D. Fanourakis. 2012. Red and blue light effects during growth on hydraulic and stomatal conductance in leaves of young cucumber plants. Acta Hort. 956:223230.

XiaoYing, L., G. ShiRong, X. ZhiGang, and J. XueLei. 2011. Regulation of chloroplast ultrastructure, cross-section, anatomy of leaves, and morphology of stomata of cherry tomato by different light irradiations of light-emitting diodes. HortScience 46:217-221. 